\title{
Cartografía de los paisajes: teoría y aplicación
}

\author{
Landscape Cartography: Theory and application
}

Eduardo Salinas Chávez, Professor Visitante Estrangeiro na Universidade Federal de Mato Grosso do Sul, Brasil, esalinasc@yahoo.com

(1) https://orcid.org/0000-0001-6392-4380

José Manuel Mateo Rodríguez, Profesor Emérito de la Universidad de La Habana, Cuba

(1) https://orcid.org/0000-0002-2568-9727.

Lucas Costa de Souza Cavalcanti, Universidade Federal de Pernambuco, Brasil,

lucascavalcanti3@gmail.com

(1) https://orcid.org/0000-0001-9096-138X

Adalto Moreira Braz, Universidade Federal de Goiás, Brasil, adaltobraz.geografia@gmail.com

(1) https://orcid.org/0000-0002-6376-6965

Resumen: El paisaje como concepto fundamental de integración en la Geografía, vuelve a tomar su papel en este nuevo siglo, caracterizado por la Globalización de la Economía y el Conocimiento y los Problemas Ambientales generados por siglos de explotación irracional de los recursos naturales de nuestro planeta y las consecuencias del Cambio Climático. Es en este contexto que presentamos aquí un análisis detallado de las principales etapas y escuelas que posibilitaron la consolidación de una teoría del paisaje como sistema integrado y su aplicación en diferentes ámbitos y regiones como parte de los esfuerzos por lograr la planificación y ordenamiento del territorio a diferentes niveles, acorde con los retos que este siglo XXI presenta para la sociedad humana, destacando el papel de la delimitación, clasificación y cartografía de las unidades de paisaje como premisa fundamental para su evaluación y conservación y las posibilidades del uso de los Sistemas de Información Geográfica, la Teledetección y la Estadística Multivariada.

Palabras claves: Paisaje, Cartografía de los Paisajes, Sistemas de Información Geográfica, Estadística Multivariada.

\begin{abstract}
The landscape as a fundamental concept of integration in Geography, returns to take its role in this new century, characterized by the Globalization of the Economy and the Knowledge, and the Environmental Problems generated by centuries of irrational exploitation of the natural resources of our planet and the consequences of Climate Change. It is in this context that we present here a detailed analysis of the main stages and schools of study of the landscape, that made possible the consolidation of a theory of landscapes as a integrated system and its application in different fields and regions as part of the efforts to achieve the planning and land use planning at different levels, in keeping with the challenges of the 21 st century presents to the human society, highlighting the role of delineation, classification and mapping of the landscape units for evaluation and conservation and the possibilities of the use of the Geographical Information Systems, Remote Sensing and Multivariate Statistical Systems.
\end{abstract}

Keywords: Landscape, Lanscape Cartography, Geographical Information Systems, Multivariate Statistical systems.

\section{Introducción}

El concepto de paisaje (paysage, paisagem, landschaft y landscape) tiene una larga historia en las ciencias y humanidades desde la antigüedad, acompañando a la propia historia y desarrollo de la sociedad desde sus inicios. Es una palabra con muchas 
acepciones, un vocablo de éxito, pero a su vez impreciso y que, por su polisemia, el sentido plural y las diversas escalas y contextos de aplicación, lo convierten en muchas ocasiones en una dificultad para la propia investigación científica.

En la Geografía, especialmente desde mediados del siglo XIX y el transcurso del siglo $\mathrm{XX}$, pasó por diferentes etapas en su concepción y aplicación, las que intentaremos analizar en esta primera parte de nuestro artículo, de forma cronológica y mediante la explicación de las diferentes escuelas de pensamiento geográfico que han contribuido a su desarrollo y consolidación como concepto básico de las ciencias geográficas, como apuntó Milton Santos $(1996 ; 2006)$ al considerar que el paisaje junto con los conceptos de espacio geográfico, territorio, región y lugar constituyen los cinco pilares básicos para construir la armazón teórico-metodológica de las ciencias geográficas en la actualidad.

El paisaje ha sido un concepto muy usado y debatido en las artes, las ciencias, la arquitectura y la antropología, entre otras, lo que está relacionado con las dimensiones principales de su percepción y análisis que son según Sancho y Del Campo (2018) cinco (artística, recreativa, científica, operativa y humanística) y que muchos estudiosos en la materia resumen en dos, a saber: visual y sistémica u holística (Figura 1). La primera considera al paisaje como la imagen del territorio o el "panorama" que percibe el observador y que se construye a partir de la combinación de formas, tamaños, colores, texturas, sombras, grados de nitidez y otros rasgos asociados, mediante procesos donde interviene no solo el paisaje real, sino la cultura e historia que el individuo tiene de forma individual y social, sobre dicho paisaje (Salinas Chávez et al., 2019; Mateo Rodríguez, 2013).

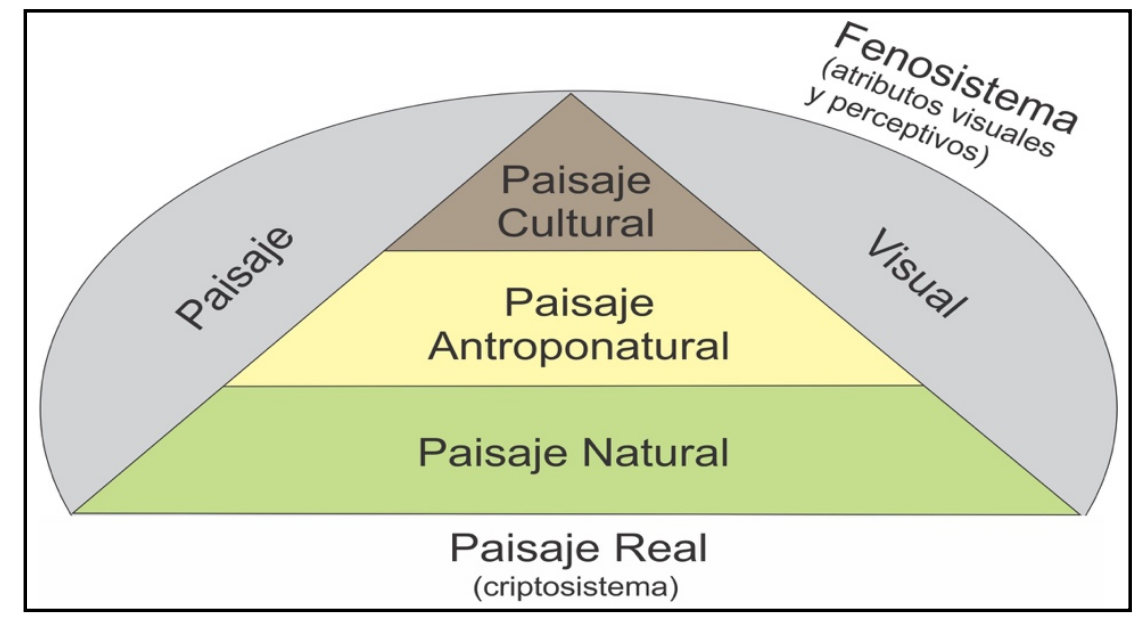

Figura 1: Las dimensiones del paisaje.

Fuente: González-Bernaldez, 1981.

La segunda dimensión se refiere al paisaje como una realidad material y objetiva, que se interesa no sólo por los caracteres fisionómico-estructurales que definen el aspecto visual ("fenosistema") del paisaje, sino también por su contenido y funcionamiento 
interior ("criptosistema"), que le da origen, mediante el estudio de las interrelaciones entre los diferentes componentes abióticos y bióticos que lo forman y que se establecen a partir del flujo e intercambio de materia y energía y posibilitan que el mismo tenga una estructura, un funcionamiento, una dinámica y una evolución particular (Muñoz, 1989; Richard, 1985; Zonneveld, 1995; Mateo Rodríguez, 2011).

El paisaje es, como destacan muchos autores, una representación filosófica y social donde cada sociedad, mediante su cultura e intencionalidad social, le imprime una particular plasticidad y naturaleza (Vitte, 2007) y una representación de un periodo histórico determinado (Ab'Sáber, 2003).

Desde el punto de vista académico y científico el origen fundacional del concepto hace casi 200 años ha estado enmarcado en considerar a la naturaleza como una totalidad que es la base de la superficie del planeta Tierra y acompañado por la aplicación de los conocimientos y herramientas cartográficas existentes en cada época, que han evolucionado junto al propio concepto de paisaje.

\section{El siglo XIX y el paisaje}

Alexander von Humboldt (1769-1859) puede ser considerado como el iniciador de los estudios científicos sobre los landschafts (paisajes). Sus numerosos viajes y publicaciones le permitieron realizar importantes aportes a la ciencia mundial, definiendo en sus obras de manera clara al paisaje como "Der totale Character einer Erdgegend" (el carácter total de una región de la Tierra), considerándolo como una totalidad natural, entendiéndolo además en sus dimensiones humana, cultural, e incluso estética y como la gente lo percibe (Zonelveld, 1995; Pedras, 2000; Vitte y Springer, 2011). Humboldt logró romper con la visión mecanicista de la naturaleza como un conjunto amorfo de componentes y elementos, al analizarla como el reflejo y la interacción holística de componentes y procesos naturales interrelacionados, examinando sus diferencias y similitudes sin perder de vista la totalidad (Wulf, 2016).

A fines de 1880, en Rusia, V. V. Dokuchaev propone el uso del concepto de paisaje (landschaft), al definir al suelo como el resultado de la interacción de los demás componentes naturales y considerarlo como el "espejo de los paisajes"; estableciendo los principios de la zonalidad latitudinal como la regularidad fundamental en la diferenciación de los paisajes y de todos los componentes y elementos naturales, e incluso humanos; y considerar por primera vez la noción de cambio de los paisajes, como la transformación ambiental (Dokuchaev, 1948). Dokuchaev pudiera considerarse como el padre de la Pedología y el fundador de la Escuela Rusa de Paisajes (Timashev, 2008).

\section{Primera mitad del siglo XX}

En Alemania, en las primeras décadas del siglo XX, Ratzel y Hettner consolidan la tradición humanista del landschaft (paisaje) que en gran parte heredó las tradiciones de la antropogeografía alemana, al mismo tiempo que las investigaciones de Schluter, Passarge y Von Richthoffen, entre otros, sustentadas en la experiencia en el estudio de los sites por los ingenieros forestales alemanes de finales de siglo XIX. Así van 
instrumentando la noción de paisaje natural y elaborando todo un sistema de unidades taxonómicas. La escuela alemana entendió los paisajes como la morfológica del territorio, visto en dos direcciones: el paisaje natural y el cultural (Martínez de Pisón, 1998).

Si bien puede considerase a Alemania la cuna de la Ciencia del Paisaje, podemos señalar que su desarrollo durante la primera mitad del siglo XX estuvo matizado por la situación geopolítica interna del país, la Segunda Guerra Mundial y la división posterior por más de 40 años de Alemania en dos países. Todo esto marcó las posiciones ideológicas de los diferentes investigadores y su mayor acercamiento a la Escuela Rusa en la Alemania Oriental (República Democrática Alemana), con destacados investigadores (Neef, 1967; 1984; Haase,1986), y a los enfoques occidentales en la Alemania Occidental (República Federal Alemana) con investigadores como Schriber (1989). Tal circunstancia representó un reflejo de la "Guerra Fría" y el enfrentamiento no solo político-ideológico que esto conllevó, sino también académico y científico. La Geografía alemana no encontró grandes posibilidades para desarrollar su idea y concepción del landschaft en estos tiempos, con la excepción del aporte de Carl Troll (1899-1975).

En esta época en los EE. UU., Carl Sauer, quien heredó la fundamentación morfológica de Humboldt, desarrolla la concepción del paisaje geográfico, incorporando la acción humana de los agentes culturales. Para él, la cultura es el agente, el área natural es el medio y el paisaje cultural es el resultado (Sauer, 1925). De esta manera logra articular en la Geografía de los Paisajes a la Geografía Física, la Geografía Histórica y la Geografía Cultural, considerando a la Geografía Humana “... la cual se ocupa únicamente de instituciones humanas o culturas, y puede ser definida como el problema de la localización de las formas de vivir..." (Sauer, 1925, p. 24) y contribuyendo al desarrollo en las escuelas anglosajonas de una vertiente cultural del paisaje que se extiende hasta nuestros días.

En Francia, los estudios del paisaje en esa época tuvieron un contexto sociocultural a partir de la corriente posibilista, desarrollada en torno al geógrafo e historiador francés Paul Vidal de La Blache (1845-1918), para quien el paisaje era la expresión del género de vida; es decir, de los instrumentos creados por los seres humanos y del estilo de vida, desde una posición y un punto de partida antropocéntrico. El concepto de región se conjuga como el área donde domina un paisaje (La Blache, 1954). El concepto de paisaje adquiriendo notable entidad como resultado tangible espacial, como "artefacto" geográfico producido por la adaptación del hombre al medio y del medio al hombre, como expresión del género de vida agrario y urbano, y como la relación entre la civilización y su espacio (Martínez de Pisón, 1998).

Por otro lado, en Rusia, a pesar de los trabajos desarrollados por diversos geógrafos (e.g. D. N. Anuchin, V. P. Semeniov y L. S. Berg) en una vertiente más cultural y sociológica de los landschaft, a partir de 1917, con el triunfo de la Revolución de Octubre, el surgimiento de la Unión Soviética y el comienzo de la construcción de una sociedad socialista, se refuerza la vertiente naturalista, eliminándose la concepción 
humanista y cultural. La ciencia del paisaje, sobre todo en la Universidad Estatal de Moscú, desarrolló un complejo sistema de levantamiento cartográfico en tres niveles taxonómicos: global, regional y local, con una visión completamente físico-geográfica en el estudio y análisis de los landschaft.

El naciente gobierno de los soviets, bajo el influjo de la necesidad de desarrollar al país de forma acelerada, estimula los estudios geográficos dirigidos a conocer los landschafts como sistemas naturales que pueden ser asimilados, ocupados y apropiados. En esta etapa tienen un papel destacado científicos como L. S. Berg (1947), A. A. Borzov, L. S. Anuchin y L. G. Ramenskii, entre otros, quienes sentaron las bases teórico-metodológicas de la Geografía de los Paisajes, estableciendo las leyes y regularidades planetarias de su desarrollo (Frolova, 2001).

\section{Segunda mitad del siglo XX}

Esta etapa está marcada por la recuperación de Europa después del fin de la Segunda Guerra Mundial, el avance del capitalismo global y la consolidación de los EE. UU. como potencia económica y científica, la creación del campo socialista en Europa Oriental, el comienzo de la "Guerra Fría", la carrera espacial y el desarrollo de las Nuevas Tecnologías de la Información, entre otros. Esto propició el amplio desarrollo de la Geografía y las ciencias afines, encaminadas a estudiar y evaluar los problemas ambientales generados como nunca antes por el mayor salto tecnológico de la humanidad desde la Revolución Industrial.

En la Escuela Rusa de paisajes esta etapa se caracteriza por la ampliación de los trabajos aplicados a tres escalas: local, regional y global, con importantes aportes de los geógrafos de la Universidad Estatal de Moscú (V. N. Solntsev, N. A. Gvodietskiy, A. I. Mijailov, V. N. Nikolaiev, A. M. Riabchikov, E. N. Lukashova y G. M. Ignatiev, entre otros) y de otras universidades (I. P. Guerasimov, A. G. Isachenko, F. N. Milkov, D. L. Armand, Yu. K. Efremov) de la entonces URSS.

La utilización de este enfoque para el estudio de diversas regiones en la URSS y en otros países de Europa, África, Asia y América Latina, incluyendo Cuba, por profesores soviéticos, posibilitó el desarrollo de una concepción integrada para la identificación, clasificación y cartografía de las unidades de paisajes a diversas escalas y en diferentes ámbitos geográficos. Este enfoque permitió establecer los límites de los paisajes, su estructura taxonómica, las regularidades de su evolución y diferenciación, lo cual constituye la base del método paisajístico para la distinción y taxonomía de las unidades de paisaje en los distintos niveles de estudio (Riabchikov, 1972; Isachenko, 1973; Solntsev, 1962; Shishenko, 1988; Nikolaiev, 2006). Así se pasó de la rígida acepción de considerar al landschaft como una formación natural, a la noción más amplia del paisaje antropogénico, bajo la forma de diferentes tipos de uso de la tierra, considerados como paisajes actuales o contemporáneos (Milkov, 1973; Riabchikov, 1972).

A partir de los años 60 del siglo pasado, con los trabajos de V. V. Sochava (19051978) se produce la introducción en los estudios del paisaje de la Teoría General de 
Sistemas formulada por Ludwig Von Bertalanffy en los años 30 del mismo siglo. Sochava en su libro "Introducción a la Teoría de los Geosistemas" (1978a) propone el concepto de Geosistema como "el espacio terrestre de todas las dimensiones, donde los componentes individuales de la naturaleza se encuentran en una relación sistémica unos con otros, y como una determinada integridad interactúan con la esfera cósmica y la sociedad humana". Esta nueva concepción se articula con los principios en los que se basó la Geografía Soviética, sustentados en una lectura y adaptación del materialismo histórico y dialéctico a los estudios del paisaje como unidad de integración geográfica y su aplicación a la solución de problemas concretos de la sociedad (Demek, 1978; Mateo Rodríguez y Silva, 2019, Mateo Rodríguez y Silva, 2006), pasando a ser reconocida y aplicada en los estudios del paisaje en la actualidad en diversos países (Monteiro, 2000; Muñoz, 1998; Mateo Rodríguez et al., 2004; Frolova, 2006, 2018).

En Alemania, Carl Troll (1966; 1971) propone la creación de la "Geoecología" como nueva disciplina científica, a partir de sus trabajos iníciales (Troll, 1939) cuando la nombró "Ecología del Paisaje", la cual definió como "la ciencia sobre los complejos naturales, que condiciona las interrelaciones entre los seres vivos y su medio en los paisajes". Según Troll, esta nueva disciplina uniría el enfoque paisajístico, que estudia la diferenciación espacial de la superficie terrestre en interrelación entre los fenómenos naturales, con el enfoque biológico-ecológico, que investiga las interrelaciones funcionales de los fenómenos y complejos naturales como sistemas ecológicos. De tal manera, esta puede ser considerada como una rama de la Ciencia del Paisaje, encaminada al conocimiento de las propiedades y funciones ecológicas de los paisajes, que estudia los paisajes naturales, antroponaturales y culturales, en los niveles global, regional y local, en calidad de medios de vida (de hábitat) de los organismos y los seres humanos y de las actividades socioeconómicas de los grupos sociales (Timashev, 2008; Troll, 1966; 1971; Klink, 1981).

La concepción de Troll sentó las bases para el desarrollo de la Ecología del Paisaje, primero en Europa y después en América del Norte y su extensión a otros países, como la conocemos hoy, con importantes aportes de investigadores europeos y norteamericanos, la realización de numerosos eventos científicos, la creación de la IALE (Internacional Asociation for Landscape Ecology) y la divulgación de numerosas publicaciones (Forman, 1995; Forman y Godron, 1986; Naveh y Lieberman, 1984; Farina 1998; Salinas Chávez y Middleton 1998; Burel y Baudry, 2002; Zee y Zonneveld, 2001; Bastian y Steinhardt, 2002; Wu, 2017).

En Francia en esta etapa se produce una profusión de trabajos desde la Geomorfología, Pedología y Biogeografía desarrollados por importantes investigadores como J. Tricart, J. Kilian (Tricart, 1982; Tricart y Kilian, 1982) y G. Bertrand, encaminados a la integración geográfica, muchos de los cuales fueron aplicados e influyeron en las nacientes escuelas geográficas de muchos países de África y América Latina y en muchos grupos de investigación en universidades españolas (Bolòs y Capdevila, 1992; Jiménez, 2000; Perez-Chacón, 2002) en Canadá (Berdoulay y Phipps, 1985). Especialmente a partir de las numerosas publicaciones 
de G. Bertrand se consolida una Escuela de Paisajes en la Universidad de ToulouseLe Mirail, que recibe la influencia de la escuela rusa por la colaboración de Bertrand con Berouchachvili y que, con la formación de geógrafos de España, América Latina y África en su seno y la colaboración académica realizada con países como México, Colombia y Brasil entre otros, fue ampliamente conocida y aplicada en numerosos estudios en diversos países. Esto fue particularmente notorio después de la traducción al español y al portugués del libro de Georges y Claude Bertrand titulado "Una Géographie Traversière. L'environnement à travers territoires et temporalités", donde se recopila sus trabajos desde los inicios en 1968 hasta el planteamiento de su muy conocido Sistema GTP (Geosistema, Territorio y Paisaje) para el estudio integrado de las dimensiones natural y cultural de los paisajes (Bertrand, 1968; Bertrand y Bertrand, 2006; Beroutchachvili y Bertrand, 1978; Moreira, 2019; Rougerie y Berouchachvili,1991; Passos, 2001; García-Romero y Muñoz, 2002).

En esta etapa aparece también una nueva escuela en los estudios geográficos integrados en Australia, la que ha sido conocida como "Levantamiento de las Tierras" inspirada en la metodología desarrollada por la FAO para los estudios de los suelos para la agricultura. Con el amplio uso de la fotointerpretación desde la década de los años 50 del pasado siglo, diversas instituciones científicas de la CSIRO (Commonwealth Scientific and Insdustrial Research Organization) desarrollaron los mapas de los Land Systems y Land Units de toda Australia a escalas medias y pequeñas. Fuera de Australia esta concepción fue aplicada en estudios en la Patagonia y el sureste de Asia (Christian y Stewart, 1968).

\section{El siglo XXI y las ciencias del paisaje}

El final del siglo XX y los inicios del siglo XXI se caracterizan por la Globalización de la Economía Mundial y del Conocimiento, por el surgimiento y desarrollo de las Redes Sociales y otras Tecnologías de la Información y las Comunicaciones, la conformación de un mundo unipolar, los numerosos conflictos bélicos regionales, la agudización de los problemas ambientales globales y la manifestación de las consecuencias del Cambio Climático. Todo esto supone para las ciencias una nueva visión postclásica, un desafío inmenso, en lo cual se incluye la Geografía, que en este periodo en muchos países ha salido de las universidades y se involucra en los trabajos de Ordenamiento y Planificación a diferentes niveles y con distintos objetivos, en los Estudios de Peligros, Vulnerabilidad y Riesgos y, de forma general, en estudios aplicados al desarrollo social.

Estos nuevos tiempos exigen cada vez más del conocimiento totalizador, abarcador, relacional; precisan de una mirada amplia, multidimensional y holística. La temática ambiental se afianza en el quehacer práctico y se convierte en una herramienta para diseñar el futuro. Para la ciencia en general, y para la Geografía en particular, es una oportunidad única para integrar todo el conocimiento fragmentado y erigirse como una potente fuerza en la sociedad del conocimiento que se va consolidando (Buzai, 2014; Ortega, 2010; Preobrazhenskii, 1998). La Ciencia del Paisaje postclásica se encamina entonces a la investigación de los sistemas correlacionales de nuevo tipo, cuyas 
propiedades adaptativas se forman no solo por los procesos naturales, sino también por procesos sociales, económicos y políticos. El concepto fundamental de la Geoecología o Ciencia del Paisaje en este nuevo siglo es el de paisaje y su interpretación como geosistema, refirmándose cada vez más este como una concepción idónea para encarar de manera inter y transdisciplinariamente la cuestión ambiental, sumando a esto la perspectiva biológica mediante la Ecología del Paisaje (Krasovstkaia, 2008; 2016; Romanova, et al., 2010; Golubev, 1999; Antipov et al., 2006; Lechniv et al., 2008).

En las últimas dos décadas, en Europa se puede observar la consolidación y ampliación de esta concepción integrada del paisaje a otros ámbitos a partir de la Convención de Paisaje aprobada en el año 2000, como resultado de un proceso largo y complejo de negociación entre los diversos países con diferentes historias y enfoques en dichos estudios (Zoido, 2009; Nogué y Sala, 2008; Brabyn, 2009; Mata, 2018).

En América Latina los estudios del paisaje desde el punto de vista geográfico se han desarrollado en diferentes momentos y bajo la influencia de diversas escuelas geográficas entre las que se destacan las escuelas francesa, alemana y rusosoviética, por lo cual en cada país este proceso de asimilación de la concepción integradora del paisaje tuvo diversas formas y matices. Estas, sin embargo, estuvieron vinculadas a los trabajos de planificación y ordenamiento desde los años 60 del siglo pasado y al papel cada vez más importante de los estudios espaciales relacionados con la problemática ambiental, estando este proceso acompañado en las últimas décadas por el uso de las Nuevas Tecnologías de la Información Geográfica (Salinas Chávez y Remond, 2015; Salinas Chávez y Middleton, 1998; Neves y Salinas Chávez, 2017; Urquijo y Bocco, 2011).

Para este articulo consideraremos al paisaje como un sistema espacio-temporal complejo y abierto que se origina y evoluciona en la interface naturaleza-sociedad, integrado por elementos naturales y antrópicos, con una estructura, funcionamiento, dinámica y evolución propias, que le confieren integridad, limites espaciales y jerarquización, constituyendo una asociación de elementos y fenómenos en constante y compleja interacción, movimiento e intercambio de energía, materia e información (Mateo Rodríguez, 2011; Bastian y Steinhardt, 2002; Kiyotani, 2014; Salinas Chávez y Remond, 2015; Isachenko, 1973).

\section{Clasificación y Cartografía de los Paisajes}

Para la clasificación y cartografía de los paisajes se han desarrollado muchos enfoques y métodos (Martinelli y Pedrotti, 2001; Salinas Chávez y Quintela, 2000; Priego et al., 2008; Ramon, Salinas y Remond, 2009; Salinas Chávez y Ramón, 2013; Salinas Chávez et al., 2013; Gómez et al., 2018) y se han elaborado diversos esquemas de trabajo y realizado experiencias a distintas escalas y en diferentes regiones y países (Abalakov y Sedykh, 2010; Cavalcanti et al., 2010; Konovalova et al., 2005; Mücher et al., 2010; Salinas Chávez y Ribeiro, 2017; Gómez y Riesco, 2010; Serrano et al., 2019). 
Todos estos métodos van encaminados a la delimitación de las unidades de paisaje y su clasificación, considerando que los paisajes existentes en un territorio determinado se forman bajo la influencia de determinados factores y procesos que pueden ser divididos en factores diferenciadores y elementos indicadores (Figura 2). Los primeros están relacionados con la zonalidad y la azonalidad, que actúan dialécticamente asociados a la energía solar que se recibe en cada lugar de la Tierra y a la energía interna, producto de los procesos de formación y desarrollo de nuestro planeta. Estos dos factores se manifiestan de forma diferente, tanto espacial como temporalmente, y determinan las regularidades más generales de la diferenciación espacial de los paisajes sobre la superficie terrestre $y$, por tanto, permiten establecer las grandes unidades de paisaje en un sistema de clasificación determinado.

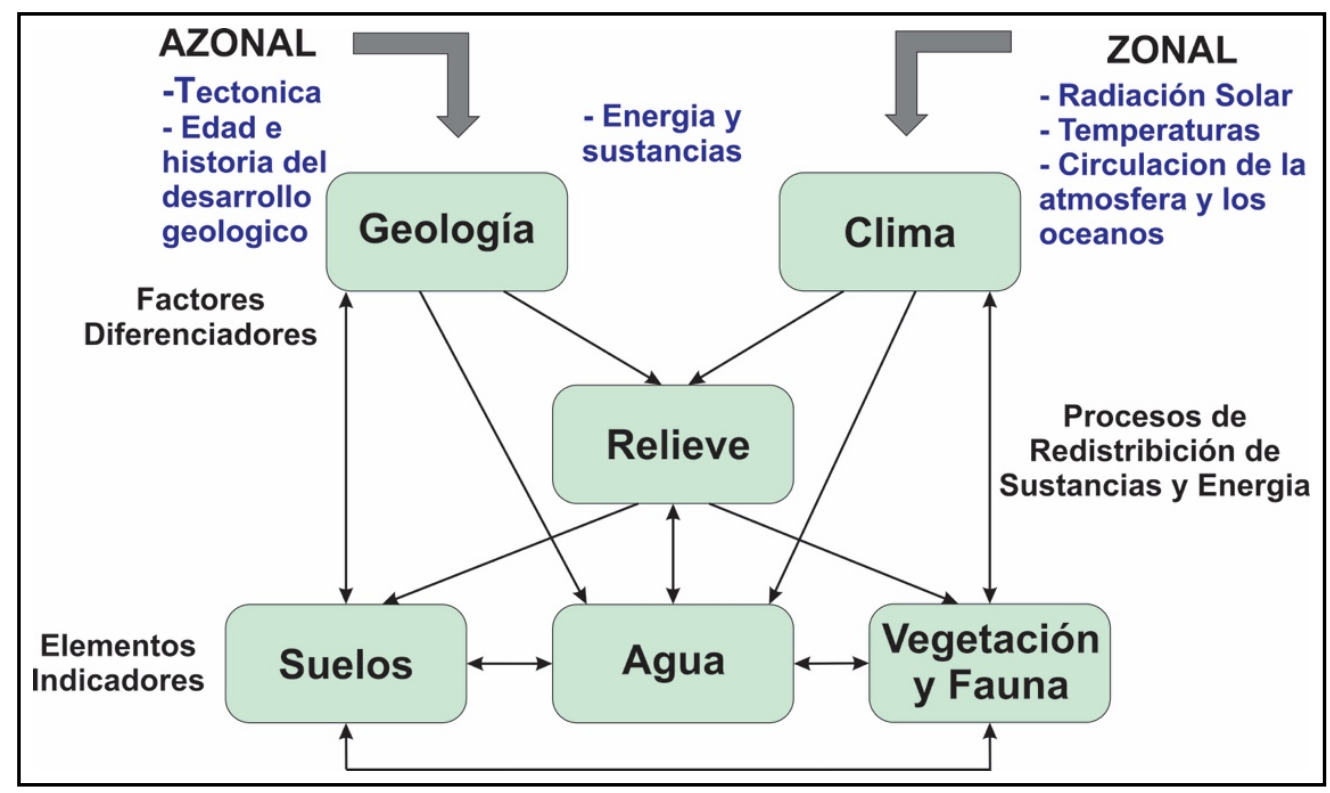

Figura 2: Factores diferenciadores y indicadores de los paisajes.

Fuente: Nikolaiev, en Mateo Rodriguez, 2011.

Estas unidades a su vez pueden ser subdividas atendiendo a los llamados elementos indicadores, que son el resultado de las diferentes combinaciones de los anteriores en un territorio en particular a partir de los procesos de redistribución de la energía y la materia que realiza el relieve y de los procesos de auto-organización de naturaleza pedogenetica y ecológica (Targulian y Krasilnikov, 2007). Adicionalmente, la formación de los diferentes paisajes es afectada por los diferentes sistemas de uso de la tierra implementados a lo largo de la historia.

\subsection{Clasificación de las unidades de paisaje}

Para la clasificación de las unidades de paisaje y utilizando como base la consideración de la existencia de factores zonales y azonales en su formación, como hemos señalado, se utilizan tres enfoques básicos que son: tipológico, regional y topológico o local. Estos últimos tienen relación con las dimensiones del territorio, la 
escala de trabajo y el comportamiento de los componentes naturales, lo que permite diferenciar y cartografiar áreas relativamente homogéneas, llamadas unidades de paisaje, usando uno o varios criterios (variables o índices diagnósticos) de manera cualitativa o cuantitativa (Salinas Chávez y Rámon, 2013).

El enfoque tipológico busca encontrar los rasgos comunes y propios, no sólo de las unidades cercanas, sino también de otras alejadas. Las unidades así diferenciadas son repetibles en el espacio y en el tiempo y se distinguen de acuerdo con los principios de analogía, homogeneidad relativa, pertenencia a un mismo tipo, repetitividad y la existencia de muchos contornos con desunión areal de los mismos.

El enfoque regional por otro lado consiste en delimitar unidades que se caracterizan por su irrepetibilidad o individualidad, en el espacio y en el tiempo, atendiendo a la estructura de sus componentes, su composición sustancial, tanto cualitativa como cuantitativa, su integridad territorial y su unidad genética.

Ambos enfoques se utilizan principalmente para estudios a escalas pequeñas en grandes territorios. Para estudios más detallados se ha utilizado el llamado enfoque topológico, que estudia la diferenciación espacial y temporal de unidades a escalas detalladas y medias (1:10 000, 1:25 000, 1:50 000). Sobre la base del análisis de los factores diferenciadores antes mencionados y de los elementos indicadores, se establece generalmente tres o cuatro niveles taxonómicos de las unidades. El superior, que puede integrarse a los enfoques anteriores, usa para su diferenciación las morfoestructuras existentes y las características mesoclimáticas del área de estudio; el segundo nivel está asociado con las mesoformas del relieve y la litología predominante; el tercero está asociado con las características de las microformas del relieve y los tipos de suelo, y el último está definido a partir del uso y ocupación del suelo.

\subsection{El mapa de paisajes}

Existe consenso en la actualidad para considerar a la cartografía de los paisajes como una síntesis cartográfica que forma parte de la cartografía temática, entendiendo al mapa de paisajes, según Salitchev (2005), como un mapa temático principal donde se representan las características fundamentales de los Complejos Territoriales Naturales y del cual se pueden derivar otros mapas de interés para la planificación y gestión ambiental, como son: mapas de las propiedades de los paisaje (estructura, funcionamiento, dinámica y evolución), mapas de la naturalidad o modificación y transformación antrópica de los paisajes y mapas del potencial de los paisajes para diversas actividades socioeconómicas, entre otros.

\subsection{El uso de los Sistemas de Información Geográfica para la Cartografía de los paisajes}

En las últimas décadas la investigación científica en Geografía encuentra un importante apoyo en las Tecnologías de la Información Geográfica. Los Sistemas de Información Geográfica (SIG) sintetizan una larga evolución del pensamiento geográfico en donde también se incluyen procedimientos metodológicos asociados a 
ellos y que favorecen según Buzai (2014) el surgimiento de dos notables revoluciones, una tecnológica y otra intelectual dentro de la Geografía como ciencia.

Las facilidades de trabajar con la información cartográfica en los SIG amplían la oportunidad de generar el inventario y caracterización de los componentes del paisaje, optimizando el trabajo con los datos e informaciones geográficas que pueden interpretarse de forma individual o mediante la combinación de los mismos, así como posibilitan calcular índices que al mezclarse permiten asignar a cada parte del territorio un tipo de paisaje (Salinas Chávez et al., 2019).

La obtención del mapa de paisajes con el empleo de los SIG puede parecer a primera vista un proceso simple, pero en realidad constituye, desde el punto de vista práctico, uno de los aspectos más complicados en la investigación del paisaje, si atendemos a diversos factores tales como las dimensiones del territorio, la escala de trabajo y las características de los componentes naturales, principalmente del relieve, el clima y la litología (Serrano, 2012; Cavalcanti, 2014; Mateo Rodríguez et al., 2004).

A pesar de las ventajas señaladas, los Sistemas de Información Geográfica no deben ser utilizados de manera automática ni todos sus resultados aceptados ciegamente; es necesario el trabajo y el conocimiento del investigador para evaluar los resultados obtenidos, así como el análisis de su calidad con el auxilio del trabajo de campo y otras informaciones recopiladas del área de estudio.

La construcción de tipologías para su uso en los SIG debe basarse en el análisis de las relaciones de dependencia conocidas entre los indicadores en asociación con los factores diferenciadores (Cavalcanti, 2016). Además, la delimitación de las unidades puede utilizar los SIG y los avances de la detección remota para aumentar la precisión en la determinación de las unidades con mayor precisión.

El uso de SIG para delimitar unidades de paisaje puede basarse en diferentes combinaciones de procedimientos, desde el más simple, basado en la digitalización, hasta operaciones complejas que combinan procesamiento digital de imágenes, álgebra de mapas y estadísticas zonales. Entre estas últimas se tiene el escaneo, la unión de "shapefiles" y la suma y vectorización basada en la clasificación de los datos temáticos considerados relevantes para la interpretación del paisaje. Estas últimas permiten definir límites precisos para las unidades mediantes la clasificación de datos de radar (relieve), satélite (vegetación) y aerogeofísica (materiales de superficie).

\section{Enfoques utilizados para la Delimitación, Clasificación y Cartografía de las Unidades de Paisaje}

Existen dos modelos fundamentales para la obtención del mapa de paisajes con el empleo de los SIG y las herramientas de análisis presentes en los mismos; a saber, división y agrupamiento. Estos modelos han sido desarrollados y aplicados desde hace unas tres décadas por diversos investigadores, en diferentes territorios y usando diversos Sistemas de Información Geográfica. 


\subsection{Enfoque por división (downscaling/top-down)}

Desde la década de los años 90 del pasado siglo, investigadores de la Facultad de Geografía de la Universidad de La Habana, Cuba, desarrollaron una propuesta metodológica para la obtención de mapas de unidades de paisaje a escalas medias y grandes con el empleo de las herramientas presentes en los SIG (Figura 3). La misma ha sido perfeccionada después de ser aplicada en numerosos trabajos en México, Cuba, Ecuador y Brasil, entre otros países (Salinas Chávez et al., 2013; Chávez, Salinas Chávez y Quintela, 2000; Salinas Chávez y Remond, 2015; Salinas Chávez y Ribeiro, 2017; Serrano et al., 2019; Quintela, Seco y Salinas Chávez, 2001; Bollo y Hernandez, 2008; Pereira, Salinas Chávez e Siqueira, 2011).

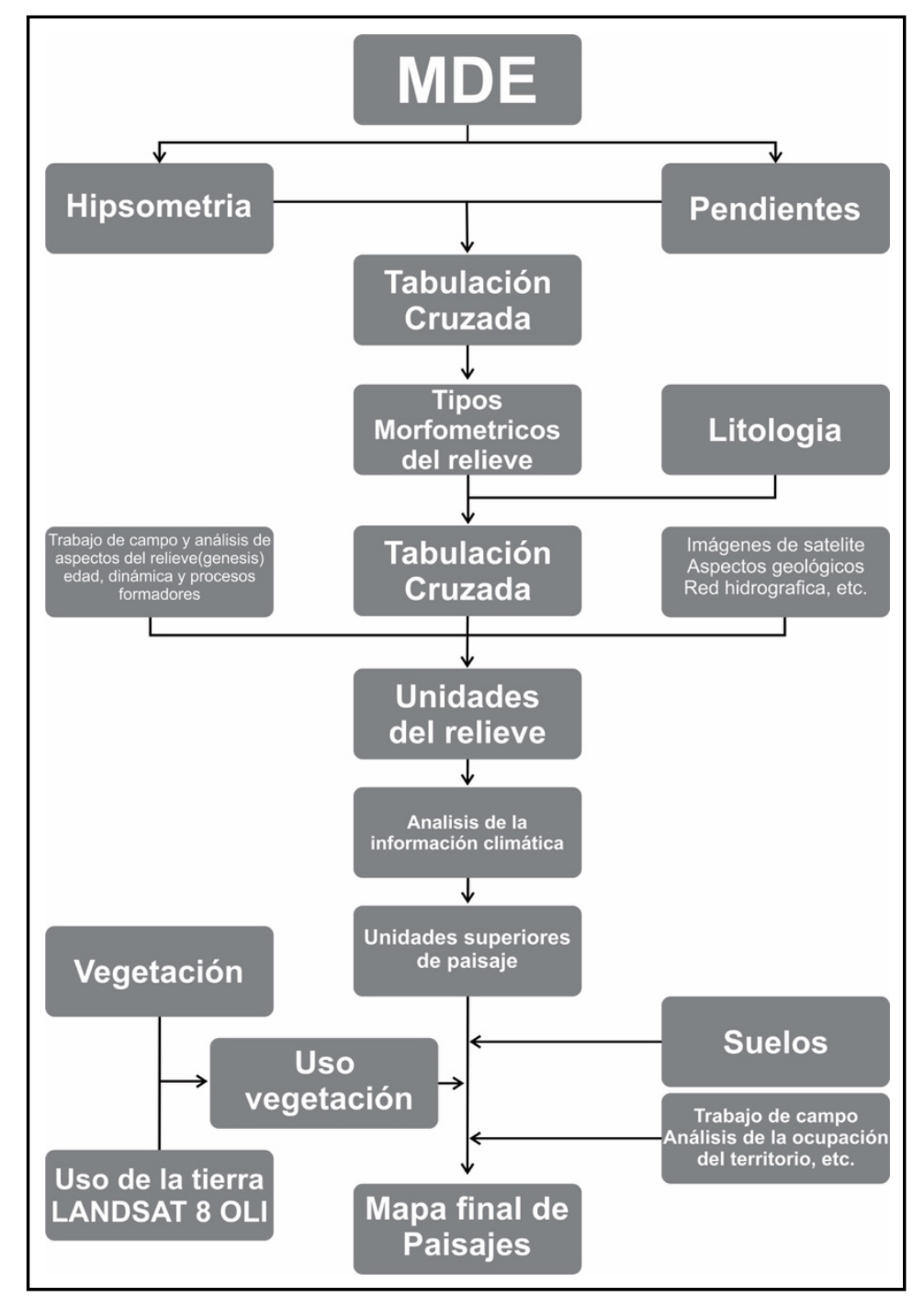

Figura 3: Modelo conceptual para la obtención del mapa de unidades de paisaje por divisón.

Fuente: Salinas Chávez y Ribeiro, 2017.

La obtención del mapa de paisajes de esta manera depende de varios supuestos. Los más comunes son: 
- La existencia u obtención de un Modelo Digital de Elevación (MDE) y de mapas temáticos del territorio: hipsometría, pendiente, litología, suelos, hidrografía, clima y uso y cobertura de la tierra, entre otros.

- La integración de los diferentes componentes mediante la superposición cartográfica y/o transferencia de atributos temáticos.

- La obtención, a partir del análisis de la información temática, topográfica y/o imágenes satelitales, de un mapa preliminar de paisajes que debe validado y corregido con el trabajo de campo.

- El conocimiento e intervención durante todo el proceso de expertos en las diferentes temáticas y la integración de estos en el análisis.

- La necesidad de cumplir con el principio del área mínima cartografiable, para lograr coherencia en la representación espacial y eficiencia en la lectura y utilidad del mapa final.

Este enfoque de clasificación y cartografía de los paisajes ha sido empleado desde hace varias décadas por diferentes investigadores en diversos países, por lo cual no explicaremos sus procedimientos de forma detallada en este articulo, sino que recomendamos a los interesados revisar las referencias bibliográficas aquí presentadas.

\subsection{Enfoque por agrupamiento (upscaling/bottom-up)}

La representación de unidades de paisaje es una tarea laboriosa, teniendo en cuenta la escala y el propósito de la aplicación a partir de la cartografía de paisajes. Elegir una escala y nivel de representación requiere un esfuerzo considerable. Esta es una pregunta fundamental para el análisis de paisajes en estudios espaciotemporales de geosistemas, que reflejan el grado de diferenciación espacial (heterogeneidad), así como la influencia de los factores naturales y antrópicos en los mismos.

La clasificación de los paisajes, según la taxonomía usada, implica la agrupación en varios niveles de los individuos geográficos según similitudes (homogeneidad) y diferencias (heterogeneidad). Por lo tanto, es necesario reflexionar sobre la jerarquía de tales individuos y establecer los medios para que la organización de los paisajes involucre procedimientos apropiados para su cartografía.

En este sentido, el enfoque jerárquico, ampliamente discutido por Klijn (1995), llevó a su autor a considerar que el primer y más importante principio de la jerarquía es que los elementos deben basarse en la desigualdad en sus relaciones. Las relaciones desiguales no ocurren dentro de un nivel; es decir, incluso si la relación entre ciertas unidades es igual, existen niveles asimétricos entre dichas relaciones, que caracterizan jerarquías distintas. Esto significa que los niveles "más altos" (superiores) están más integrados u organizados que los niveles "más bajos" (inferiores).

Al igual que Cavalcanti y Corrêa (2016) y Monteiro (2000), Klijn (1995, p. 33) también afirmó que "esto plantea la cuestión de qué criterios deben usarse para organizar y ordenar los fenómenos: cuáles son exactamente las asimetrías [o heterogeneidades] 
¿En qué niveles jerárquicos deben basarse?" (Klijn, 1995, p. 33). Por lo tanto, Sochava (1978 b, p. 8) ya admitió que "ninguna clasificación es absoluta; es necesario modificarla y perfeccionarla ".

"Los análisis realizados en multiescala aún pueden clasificarse según el sentido de la detección de la jerarquía. Saliendo de escalas geográficas grandes a escalas más pequeñas, uno tiene un enfoque de escala descendente. A partir de escalas geográficas pequeñas para escalas más grandes, se tiene un enfoque ascendente" (Cavalcanti y Corrêa, 2013, p. 153). Este enfoque de abajo hacia arriba toma como base el agrupamiento de unidades inferiores en unidades superiores, considerando el enfoque tipológico y el uso de herramientas de agrupación estadística tipo cluster para crear modelos de grupos de variables con un alto número de unidades de paisaje.

Presentamos a continuación un trabajo, donde se agrupó unidades inferiores en jerarquías superiores con un cierto grado de similitud, llevado a cabo en el municipio de Mineiros, en el estado de Goiás, Brasil. La tipología presentada aquí se realizó mediante el análisis de agrupamiento (cluster), teniendo en cuenta estadísticas multivariadas.

La síntesis de las variables de morfoestructura, geología, geomorfología, pedología, topografía, densidad de drenaje y uso y cobertura de la tierra, dio lugar a un gran número de unidades de paisaje (272). Este hecho condicionó el interés en la delimitación de grupos (clusters) que fuesen similares (Figura 4). Esta técnica, comúnmente usada en estadística, cumple con los principios analizados para la cartografia de los paisajes, cuyo interés es determinar elementos homogéneos en su estructura y heterogéneos entre ellos, capaces de establecer "agrupamientos" o "divisiones" en diferentes jerarquías, simplificando finalmente su representación cartográfica.

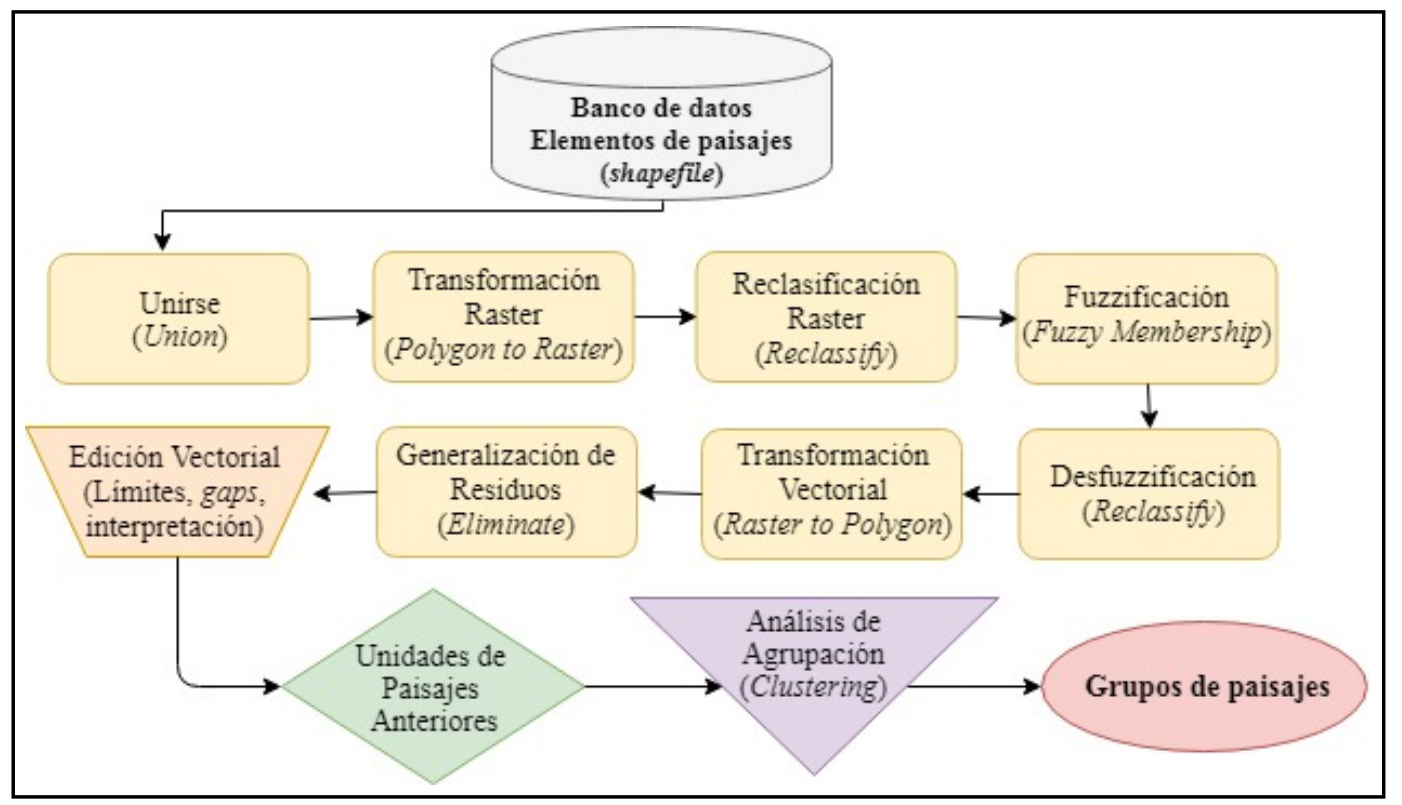

Figura 4: Diagrama de flujo de procedimientos para la obtención de los grupos de paisajes. 
La delimitación de los conjuntos de individuos (grupos de paisajes) con características similares tomó en cuenta los elementos y su interrelación en la estructura de los paisajes. El resultado de este procedimiento es un dendrograma que agrupa las unidades de paisaje a diferentes niveles de distancia de los grupos formados (Figura 5). Esta es una de las principales ventajas de los algoritmos jerárquicos, que "no solo proporcionan los clusters obtenidos, sino también todas las estructuras de datos y permiten obtener fácilmente subconjuntos dentro de estos datos" (Linden, 2009, p. 29).

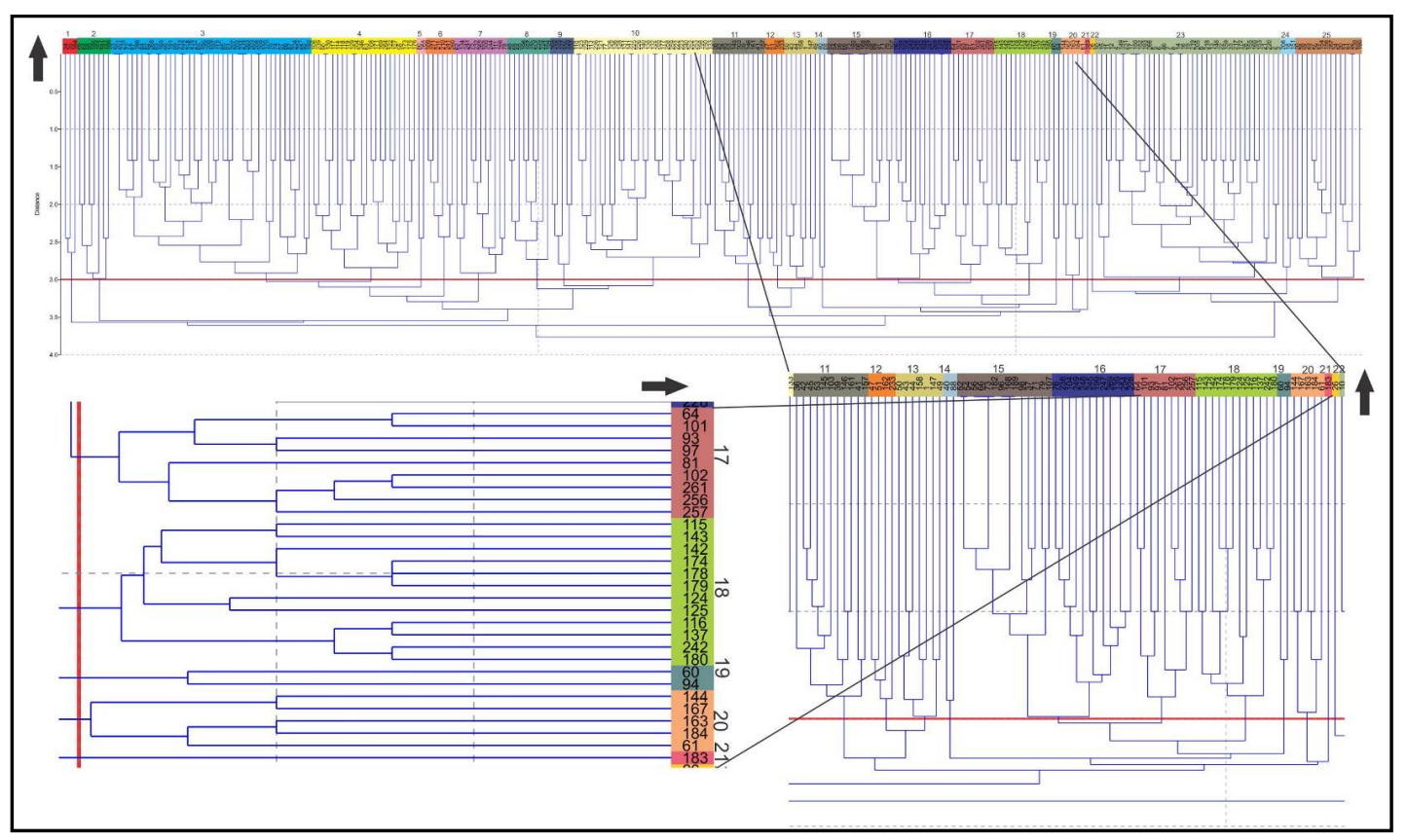

Figura 5: Ejemplo de dendrograma resultante de un análisis cluster

Finalmente, fueron agrupadas las 272 unidades inferiores, en 25 grupos de paisajes, según su similitud con la agrupación obtenida por el dendrograma resultante de la operación estadística realizada (Figura 6).

Al principio no fue posible establecer una regla, o incluso una tendencia, en el sentido genético del acondicionamiento del paisaje, lo que indica una regulación en la formación y jerarquía de los geosistemas a partir de los elementos utilizados para delimitar las unidades del paisaje (morfoestructura, geología, altimetria, pendiente, densidad de drenaje, geomorfología, suelos y cobertura y uso del suelo). 


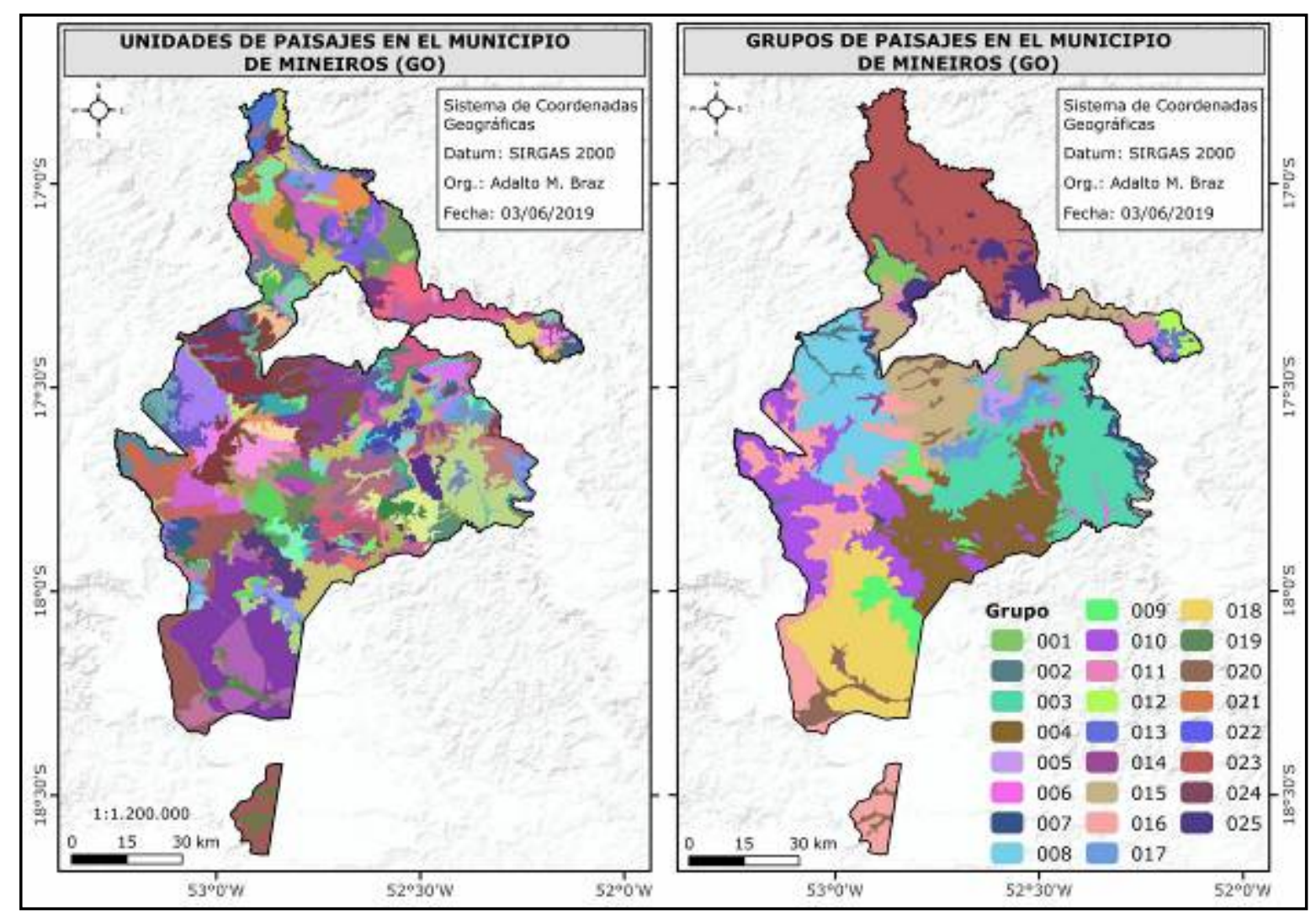

Figura 6: Cartografía de las unidades inferiores y grupos de paisajes en Mineiros (GO).

La agrupación obedece a la premisa de uno de los modelos teóricos y conceptuales de los geosistemas: presentar un resultado satisfactorio donde los atributos utilizados ejerzan una influencia descentralizada sobre la formación de las unidades de paisajes; es decir, no debe haber ningún atributo que sea preponderante o que condicione la formación y la agrupación de las 272 unidades en 25 grupos de paisajes.

Se consideró que el uso de técnicas estadísticas (clustering) fue relevante en la optimización de los procesos. Aun así, se debe enfatizar que esta es una posibilidad para apoyar la cartografía de los paisajes, pero no puede, al menos con la experiencia aquí presentada y discutida, ser entendida como la orientación principal e innegable para la delimitación de unidades de paisaje. Como ya se presentó, es necesario diferenciar la significación estadística de la significación espacial en los límites presentados por las agrupaciones de paisajes. Finalmente, queremos señalar que los procedimientos utilizados y los resultados obtenidos, pueden contribuir a la búsqueda de nuevas técnicas para la cartografía de los paisajes.

\section{Consideraciones Finales}

La ciencia del paisaje tiene una historia larga y antigua y su desarrollo tuvo lugar en estrecha relación con la planificación territorial. A partir de los trabajos de Humboldt y los avances en la Geografía y la Ecología, las unidades delimitadas y cartografiadas pueden ser entendidas como geosistemas, originados por la interacción e interdependencia entre los factores diferenciadores y su manifestación en los 
geomorfismos y grupos pedogénicos y ecológicos que se distribuyen en la superficie terrestre.

El paisaje deja de ser a fines del siglo XIX solo un motivo de las artes, especialmente la pintura, y comienza a entenderse como un sistema espacio-temporal, organizado a partir de los flujos de energía y materia, lo que le garantiza una estructura, funcionamiento, dinámica y evolución. Este geosistema, como una marca en la superficie terrestre, interactúa dialécticamente con la historia humana, influyendo y siendo influenciado por el uso de la tierra y el desarrollo de la sociedad.

El conocimiento y cartografía de los paisajes es esencial para la toma de decisiones en temas de planificación y ordenamiento territorial en un mundo globalizado, con serios problemas ambientales asociados con el desarrollo acelerado y muchas veces inadecuado de la sociedad humana, a lo cual se suman ahora las consecuencias del Cambio Climático. A principios del siglo XXI, las aplicaciones de los SIG y la Teledetección a la cartografía del paisaje se multiplicaron en términos de mejorar la precisión y la exactitud de la delimitación y cartografía de las unidades.

A pesar de todos estos avances, persisten algunos desafíos. La taxonomía de los paisajes, por ejemplo, todavía carece de una contribución más sólida que refleje la influencia de los factores diferenciadores en los elementos indicadores y señala fuentes de incertidumbre en el resultado de la autoorganización de los suelos y la vegetación, y el papel del uso de la tierra en estos procesos.

En relación con el enfoque upscaling, su uso tiene la ventaja de promover límites más precisos, en la medida en que en el enfoque downscaling la precisión de los limites de las unidades a veces tiende a ser comprometida, pues son heredados limites de las unidades anteriores. Por otra parte, la utilización de agrupamientos estadísticos para la identificación de los niveles jerárquicos (taxones) aun precisa de una evaluación mas amplia en relación con la búsqueda de datos de entrada mas coherentes, medidas de agrupamiento más adecuadas y también en cuanto al significado paisagístico de los grupos identificados, lo que en el otro enfoque está mejor definido.

A pesar de que la era de la ciencia del paisaje se consolida, hay varias cuestiones en juego y debe nutrirse de los aportes instrumentales de los Sistemas de Información Geográfica, la Teledetección y la Estadística Multivariada. Corresponde al geógrafo ampliar su arsenal teórico y metodológico para una comprensión más amplia de los paisajes, un paso esencial para generar productos adecuados a las demandas de un mundo dinámico y en rápida evolución.

\section{Bibliografia}

Ab'saber, A. N. (2003). Os domínios de natureza no Brasil: potencialidades paisagísticas. São Paulo: Ateliê.

Abalakov, A. D., Sedykh, S. A. (2010). Regional-typological study and mapping of geosystems: analysis of the implementation. Geography and Natural Resources, 31, 317-323.

Antipov, A. N., Kravchenko, V. V., Semenov, Yu. M., Drozdov, A. N. V., Gagarinova, O. V., Fedorov, V. N., Rogovskaya, N. V., Plyunin, V. M., Suvorov, E. G., editors. (2006). 
Landscape planning: tools and experience in implementation Irkutsk: V.B. Sochava Institute of Geography, SB RAS Publishers.

Bastian, O., Steinhardt, U. (2002). Development and perspectives of landscape ecology. Dordrecht: Kluwer Academic Publishers.

Berdoulay, V., Phipps, M. (1985). Paysage et Système: de l'organisation écologique à l'organisation visuelle. Ottawa: Editions de l'Université d'Ottawa.

Berg, L. S. (1947). Zonas geográficas de la Unión Soviética. Tomo 1., Moscú: editorial estatal de literatura geográfica. [En Ruso].

Beroutchachvili, N., Bertrand, G. (1978). Le Geosystéme ou Systéme Territorial Naturel. Revue Géographique des Pyrinées et du Ouest, 49(2), 167-180.

Bertrand, G. (1968) Paysage et géographie physique globale. Esquisse méthodologique. Revue Géographique des Pyrénées et du Sud-ouest, 39(3), 249-272.

Bertrand, C., Bertrand, G. (2006). Geografía del medio ambiente. el sistema GTP: Geosistema, Territorio y Paisaje. Granada: Universidad de Granada.

Bolòs i Capdevila, M. (1992). Manual de Ciencia del paisaje, teoría, métodos y aplicaciones. Barcelona: Editorial Masson.

Bollo, M., Hernández, J. R. (2008). Paisajes físico-geográficos del noroeste del estado de Chiapas, México. Investigaciones Geográficas, Boletín, 66, 7-24.

Brabyn, L. (2009). Classifying landscape character. Landscape Research, 34, 299-321.

Burel, F., Baudry, J. (2002). Ecología del Paisaje, Conceptos, Métodos y Aplicaciones. Madrid: Ediciones Mundi- Prensa.

Buzai, G. (2014). Neogeografía y sociedad de la información geográfica. Una nueva etapa en la historia de la Geografía. Boletin del Colegio de Geógrafos de Perú, 1, 1-12.

Cavalcanti, L. C. S. (2014). Cartografia de paisagens: fundamentos. São Paulo: Oficina de Textos.

Cavalcanti, L. C. S. (2016). Geossistemas do Semiárido Brasileiro: considerações iniciais. Cadernos de Geografia, 26(2), 214-228.

Cavalcanti, L. C. S., Corrêa, A. C. B. (2013). Problemas de hierarquização espacial e funcional na ecologia da paisagem: uma avaliação a partir da abordagem geossistêmica. Geosul, 28(55), 143-162.

Cavalcanti, L. C. S., Corrêa, A. C. B. (2016). Geossistemas e Geografia no Brasil. Revista Brasileira de Geografia, 61(2), 3-33.

Cavalcanti, L. C. S, Corrêa, A. C. B, Araújo Filho, J. C. (2010). Fundamentos para o mapeamento de geossistemas: uma atualização conceitual. Geografía, 35, 539-551.

Christian, C. S., Stewart, G. A. (1968). Methodology of integral surveys. Proceedings of the Toulouse Conference an aerial surveys and integrated studies (p. 233-280). UNESCO.

Demek, J. (1978). The Landscape as a Geosystem. Geoforum, 9, 29-34.

Dokuchaev, V. V. (1948). La teoría sobre las zonas naturales. Moscu: Geografiz. (En Ruso)

Farina, A. (1998). Principles and Methods in Landscape Ecology. London: Chapman and Hall. 
Forman, R. T. T. (1995). Land mosaics. The Ecology of landscape and regions. Cambridge: Cambridge University Press.

Forman, R. T. T., Godron, M. (1986). Landscape Ecology. New York: John Wiley and Sons.

Frolova, M. (2001). Los orígenes de la Ciencia del Paisaje en la geografía rusa. Scripta Nova, 102(7), 1-13.

Frolova, M. (2006). Desde el concepto de paisaje a la Teoría de geosistema en la Geografía rusa: ¿hacia una aproximación geográfica global del medio ambiente?”. Ería, 70, 225-235.

Frolova, M. (2018). From the Russian/Soviet landscape concept to the geosystem approach to integrative environmental studies in an international context. Landscape Ecology, 1-18.

García-Romero, A., Muñoz, J. (2002). El paisaje en el ámbito de la geografía. Ciudad de México: Instituto de Geografía.

Gómez, J., Riesco, P. editors. (2010). Marco conceptual y metodológico para los paisajes españoles: aplicación a tres escalas espaciales. Sevilla: Consejería de Obras Públicas y Vivienda.

Gómez, J., Riesco, P., Frolova, M., Rodríguez, J. (2018). The landscape taxonomic pyramid (LTP): a multi-scale classification adapted to spatial planning. Landscape Research, 43(7), 984-999.

González-Bernáldez, F. (1981). Ecología y Paisaje. Madrid: Editorial H. Blume.

Haase, G. (1986). Landscape Ecology (Abastract of Lectures) Leipzig: Int. Train. Course, Inst. de Geog. y Geoecologie.

Isachenko, A. G. (1973). Principles of Landscape Science and Physical Geographic Regionalization. Melbourne: University Press.

Jiménez Olivencia, Y. (2000). De los complejos naturales a los paisajes: el modelo de Sierra Nevada. Cuadernos Geográficos, 30, 47-63.

Kiyotani, I. (2014). O conceito de paisagem no tempo. Geosul, 29(57), 27-42.

Klijn, J. A. (1995). Hierarchical concepts in landscape ecology and its underlying disciplines. Report 100. Wageningen: DLO WinandStaring Centre.

Klink, H. J. (1981). Geoecologia e regionalização natural (bases para pesquisa ambiental). Biogeografia, 17, $32 \mathrm{p}$.

Konovalova, T. I., Cherkashin, A., Bessolitsyna, E. (2005). Landscape Interpretation Mapping, Novosibirsk: Nauka.

La Blache, P. V. (1954). Princípios de geografia humana. 2. ed. Lisboa: Cosmos.

Lechniv, J., Kulczyk, S., Malinowska, E., Szumacher I. (2008). The problems of landscape ecology. Vol. XX Landscape classification. Theory and practice. Warszawa: Assoc. for Landscape Ecology.

Martinelli, M., Pedrotti, F. A. (2011). A cartografia das unidades de paisagem: questões metodológicas. Revista do Departamento de Geografía, 14, 39-46.

Martínez de Pisón, E. (1998). El concepto de paisaje como instrumento de conocimiento ambiental. En: E. Martínez de Pisón E, editor. Paisaje y medio ambiente (p. 45-56). Madrid: Fundación Duques de Soria, Universidad de Valladolid. 
Mata, R. (2018). Paisaje. En: Sancho J, Del Campo A, editors. España en mapas. Una síntesis geográfica. Atlas Nacional de España del siglo XXI (p. 479-498). Madrid: Instituto Geográfico Nacional de España, Centro Nacional de Información Geográfica.

Mateo Rodríguez, J. M., Silva, E. V., Cavalcanti, A. P. B. (2004). Geoecologia das paisagens. uma visão geossistémica da análise ambiental. Fortaleza: Editora UFC.

Mateo Rodríguez, J. M., Silva, E. V. (2006). Para una interpretación epistemológica de la Geografia a partir de la Dialéctica. Mercator, 4 (9), 55-68.

Mateo Rodríguez, J. M. (2011). Paisajes naturales. Geografía de los paisajes, primera parte. La Habana: Editorial Universitaria.

Mateo Rodríguez, J. M. (2013). Geografía de los Paisajes. segunda parte. Paisajes culturales. La Habana: Editorial Universitaria Félix Varela.

Mateo Rodríguez, J. M., Silva, E. V. (2019). Teoria dos geosistemas. O legado de V.B. Sochava. Volume I Fundamentos teórico metodológicos. Fortaleza: Edições UFC.

Milkov, F. N. (1973). El hombre y los paisajes. Rasgos de la ciencia del paisaje antropogénica. Moscú: Misl.

Monteiro, C. A. F. (2000). Geossistemas: a história de uma procura. São Paulo: Contexto.

Moreira, R. (2019). A Torre e o palimpsesto: Tricart e Ab'saber olhados pelo olhar da totalidade homem-meio. Ciência Geográfica, 23(1), 7-16.

Mücher, C. A., Klijn, J. A., Wascher, D. M., Schaminé, J. H. (2010). A new European landscape classification (LANMAP): a transparent, flexible and user-oriented methodology to distinguish landscapes. Ecological Indicators, 10, 87-103.

Muñoz, J. (1989). Paisaje y Geografía. Arbor, 518(519), 219-234.

Muñoz, J. (1998). Paisaje y geosistema. Una aproximación desde la geografía física. En: Martínez de Pisón E, editor. Paisaje y medio ambiente (p. 45- 56). Madrid: Fundación Duques de Soria, Universidad de Valladolid.

Naveh, Z., Liberman, A. S. (1984). Landscape ecology: theory and application. New York: Springer Verlag.

Neef, E. (1967). Die theoretischen Grundlagen der Landschaftslehre [The theoretical foundations of landscape study]. Leipzig: VEB Hermann Haack.

Neef, E. (1984). Applied Landscape Research. Applied Geography and Development, 24, 3858.

Neves, C. E., Salinas Chávez, E. (2017). A paisagem na geografia física integrada: impressões iniciais sobre sua pesquisa no Brasil entre 2006 e 2016. Revista do Departamento de Geografia, Edição Especial SBGFA, 124-137.

Nikolaiev, V. A. (2006). Ciencia del paisaje. Seminarios y tareas prácticas. Facultad de Geografía de la Universidad Estatal de Moscú. (En Ruso)

Nogué, J., Sala, P. (2008). El paisaje en la ordenación del territorio. Los catálogos de paisaje de Cataluña. Cuadernos Geográficos, 43, 69-98.

Ortega, N. (2010) El lugar del paisaje en la geografía moderna. Estudios Geográficos, 269, 367-393. 
Passos, M. M. (2001). A conceituação da paisagem. Revista Formação, 7(1), 131-144.

Pedras, L. R. V. (2000). A paisagem em Alexander Von Humboldt: o modo descritivo dos quadros da natureza. Revista USP, 46, 97-114.

Pereira, G. E., Salinas Chávez, E., Siqueira, M. E. (2011). O estudo das unidades de paisagem do bioma Pantanal. Revista Ambiente \& Água, 7(1), 89-103.

Perez-Chacón, E. (2002) Unidades de paisaje: aproximación científica y aplicaciones. En: Zoido F, Venegas C, editors. Paisaje y Ordenación del territorio (p. 122-135). Sevilla: Junta de Andalucia.

Preobrazhenskii, V. S. (1998). Ostrye problemy landshaftovedeniya na rubezhe vekov [Acute problems of landscape science on the boundary between centuries]. Izvestiya Akademii Nauk: Seriya Geograficheskaya, 3, 14-19.

Priego, A., Bocco, G., Mendoza, M., Garrido, A. (2008). Propuesta para la generación semi automatizada de unidades de paisajes. Fundamentos y métodos. Ciudad de México: Instituto Nacional de Ecología.

Quintela, J., Seco, E., Salinas Chávez, E. (2001). Geomorphological and landscape mapping of the Cuyutlan Lagoon. GIS for Natural Environment Mapping, GIM International. p. 44-47.

Ramón, A. M., Salinas Chávez, E., Remond, R. (2009). Diseño Metodológico para la elaboración de mapas de paisajes con el uso de los SIG: aplicación a la cuenca alta del río Cauto, Cuba. Geografía y Sistemas de Información Geográfica (GeoSIG), 1(1), 95-108.

Riabchikov, A. M. (1972). Estructura y dinámica de la Esfera geográfica, su desarrollo natural y la transformación por el hombre. Moscú: Editorial MIR.

Richard, J. F. (1985). Le paysage: analyse et synthèse. Paris: Lett. Et Sci. Hum.

Rougerie, G., Beroutchachvili, N. (1991). Géosystèmes et Paysages: bilan et méthodes. Paris: A. Colin.

Salitchev, K. A. (2005). Cartografía. 2. ed. La Habana: Editorial Pueblo y Educación.

Salinas Chávez, E., Middleton, J. (1998). Lanscape ecology as a tool for sustainable development in Latin America. Consultado em: www.brocku.ca/epi/lebk/lebk.html/.

Salinas Chávez, E., García, A. E., Miravet, B. L., Remond, R., Cruañas, E. (2013). Delimitación, clasificación y cartografía de los paisajes de la cuenca Ariguanabo, Cuba, mediante el uso de los SIG. Revista Geográfica del IPGH, 154, 9-30.

Salinas Chávez, E., García-Romero, A., Serrano de la Cruz, M. A., Méndez A., Moretti, E. C. (2019). Las dimensiones del paisaje como recurso turístico. En: Suárez, R.; Reyes, A. \& Pintó, J. editors. Turismo i paisatge (p. 131-140), Documenta Universitaria, Girona.

Salinas Chávez, E., Quintela, J. (2000). Paisajes y ordenamiento territorial, obtención del mapa de paisajes del estado de Hidalgo en México a escala media con el apoyo de los SIG, Alquibla. Revista de Investigaciones del Bajo Segura, 7, 517-527.

Salinas Chávez, E., Ramón, A. (2013). Propuesta metodológica de la delimitación semiautomátizada de unidades de paisaje de nível local. Revista do Departamento de Geografia, 25, 1-19.

Salinas Chávez, E., Ramón, A., Trombeta L. (2019). La cartografia de los paisajes y los sistemas de información geográfica: aspectos conceptuales y metodológicos. En: Seolin L, 
Salinas Chávez E, editors. Cartografía biogeografica e da paisagem (p. 37-54). Volume 2. Tupã: ANAP.

Salinas Chávez, E., Remond, R. (2015). El enfoque integrador del paisaje en los estudios territoriales: experiencias prácticas. En: Garrocho C, Buzai G, editors. Geografía aplicada en Iberoamérica: avances, retos y perspectivas (p. 503-542). Zinacantepec: El Colegio Mexiquense.

Salinas Chávez, E., Ribeiro, A. F. (2017). La cartografía de los paisajes con el empleo de los sistemas de información geográfica: caso de estudio Parque Nacional Sierra de Bodoquena y su entorno, Mato Grosso do Sul, Brasil. Geografía y Sistemas de Información Geográfica (GeoSIG), 9(9), 186-205.

Sancho, J., Del Campo, A. (2018). España en mapas. una síntesis geográfica. Compendio del Atlas Nacional de España del siglo XXI. Madrid: Instituto Geográfico Nacional de España, Centro Nacional de Información Geográfica.

Santos, M. (1996). De la totalidad al lugar. Barcelona: Editorail Oikos-tau.

Santos, M. (2006). A natureza do espacio. Técnica e tempo. Razão e emoção. 4. ed. São Paulo: Editora da Universidade de São Paulo.

Sauer, C. (1925). The morphology of landscape. Berkeley: University of California.

Schriber, K. F. (1989). The history of landscape ecology in Europe. En: Zonneveld IS, Forman RT, editors. Changing lanscapes: an ecologicaal perspective (p. 21-33). Berlin: SpringerVerlag.

Serrano, D. (2012). El papel del relieve en la definición de unidades de paisaje. Cuadernos de Investigación Geográfica, 32(2), 123-145.

Serrano, D., García, A., García, L. A., Salinas Chávez, E. (2019). Un nuevo método de cartografía del paisaje para altas montañas tropicales. Cuadernos Geográficos, 58(1), 83100. http://dx.doi.org/10.30827/cuadgeo.v58i1.6517.

Shishenko, P. C. (1988). Geografia fisica aplicada. Kiev: Editorial Visha Skola. (En Ruso)

Sochava, V. B. (1978a). Introducción al estúdio de los geosistemas. Novosibirsk: Science, Siberian Branch. (En Ruso)

Sochava, V. B. (1978b). Por uma teoria de classificação dos geossistemas de vida terrestre. Biogeografia, 14, 1-24.

Solntsev, N. G. (1962). Basic problems in Soviet landscape science. Soviet Geography, 3, 315.

Targulian, V. O., Krasilnikov, P. V. (2007). Soil system and pedogenic processes: Selforganization, time scales, and environmental significance. Catena, 71, 373-381.

Timashev, I. E. (2008). El componente geoecológico principal del paisaje terrestre. En: Alekseev BA, editor. El mundo de la geoecología (p.11-20). Moscú: GEOS.

Tricart, J. (1982). Paisagem e ecologia, Inter-Facies, escritos e documentos. São José do Rio Preto: IBILCE-UNESP.

Tricart, J., Kilian, J. (1982). La Ecogeografia y lo ordenación del medio natural. Barcelona: Editorial Anagrama. 
Troll, C. (1939). Luftbildplan und ökologische Bodenforshung. Zeitschr. D. Gesellschaft. F. Berlin: Erdkunde zu Berlin.

Troll, C. (1996). Landscape ecology, Amsterdam: First ITC/UNESCO Seminar on Integrated Survey Delft, Especial Publication.

Troll, C. (1971). Landscape ecology (Geoecology) and Biogeocenology. Geoforum, 8, 43-46.

Urquijo, P., Bocco, G. (2011). Los estudios de paisaje y su importancia en México, 1970-2010. Journal of Latin American Geography, 10(2), 37-63.

Vitte, A. C. (2007). O Desenvolvimento do conceito de paisagem e a sua inserção na geografia física. Mercator, 6(11), 23-38.

Vitte, A. C., Springer, K. S. (2011). A ciência humboldtiana: relações entre a sensibilidade e a mensuração na gênese da geografia física. Revista do Departamento de Geografia, 21, 167-177.

Wu, J. (2017). Thirty years of Landscape ecology (1987-2017): retrospects and prospects. Landscape Ecology, 32, 2225-2239.

Wulf, A. (2016). A invenção da natureza: a vida e as descobertas de Alexander Von Humboldt, São Paulo: Editorial Planeta.

Zee, D., Zonneveld, I. S. (2001). Landscape Ecology. applied in land evaluation, development and conservation: some worldwidwe selectes examples. Enschede: TC Publication; IALE Publication.

Zoido, F. (2009). El convenio europeo del paisaje. En: Fábregas JB, Ramos AC, editors. Gestión del paisaje (p. 299-315). Barcelona: Ariel.

Zonneveld, I. S. (1995). Land Ecology. Amsterdam: SPB Academic Publi.

Artigo recebido em / Received on: 25/07/2019

Artigo aceite para publicação em / Accepted for publication on: 22/10/2019 
Salinas Chávez et al. / Physis Terrae, Vol. 1, n 1, 2019, 7-29

Página intencionalmente deixada em branco 